\title{
A method for automatically recording topographical differences in pigeons' keypecking for food and water reinforcers
}

\author{
RONALD W. SKELTON, MARCIA L. SPETCH, and DONALD M. WILKIE \\ University of British Columbia, Vancouver, British Columbia V6T IW5, Canada
}

\begin{abstract}
The topography of pigeons' keypecking responses for food reinforcers is visibly different from the keypeck topography for water reinforcers. Previous methods of recording topographies have been complex and not without problems. A simple inexpensive modification of a standard pecking key permits the recording of two components of the topography in sufficient detail to allow the detection of these topographical differences.
\end{abstract}

A growing literature (e.g., Boakes, Poli, Lockwood, \& Goodall, 1978; Hull, 1977; Woodruff \& Starr, 1978) suggests that the topography of conditioned responses is influenced by the type of reinforcer. It is of some theoretical importance that these topographies resemble the species-typical appetitive and consummatory responses for the reinforcer (e.g., Hearst, 1975; Hearst \& Jenkins, 1974; Jenkins, Barrera, Ireland, \& Woodside, 1978; Schwartz \& Gamzu, 1977).

Pigeons' keypecking under both operant (Wolin, 1968) and Pavlovian (Jenkins \& Moore, 1973) conditioning procedures differs when grain and water serve as reinforcers. When grain reinforcement is used, keypecks have been characterized as rapid, forceful, short in duration, and open-beaked. With water reinforcement, pecks appear slower, less forceful, longer in duration, and closed-beaked.

While topographical differences in keypecking for food and water reinforcers are readily visible to an observer, the techniques used in the past for recording topographical differences have been problematic. Jenkins and Moore (1973), for example, recorded keypecking on selected trials on videotape or film and then had human observers rate the topographies as resembling the pigeon's eating or drinking behaviors. Although interrater reliability was good, the exact dimensions used by the raters to distinguish the topographies are difficult to specify. Moreover, this technique is tedious, and it does not readily lend itself to long-term investigations of differenccs in keypecking topography.

Jenkins and Moore (1973) also presented sample photographs of pecks on food and water trials. While differences in the topographies on food and water trials

This work was supported by the Natural Sciences and Engineering Research Council of Canada. The assistance of R. Summers and D. King in testing subjects is acknowledged. Send reprint requests to Donald $M$. Wilkie, Department of Psychology, 2075 Wesbrook Place, the University of British Columbia, Vancouver, British Columbia V6T 1W5, Canada. clearly were visible, it is impossible to know how typical these differences were.

Jenkins and Moore (1973) also placed a HewlettPackard/Sanborn displacement transducer on the key and obtained continuous recordings on chart paper of both the duration and force of pecks. Because of the cumbersome nature of such analog recordings, no quantitative analyses of these data were conducted and only sample records were presented. A similar procedure was used by Woodruff (1979) and Woodruff and Williams (1976).

We have developed a simple technique that can be easily and inexpensively implemented and that readily lends itself to automated recording of force and duration in pigeons' keypecking for food or water reinforcers. Although this technique can be used with conventional relay or solid state programming equipment, we employ a Data General NOVA 3/12 minicomputer to arrange experimental conditions and to record data on a disk for later analysis.

The technique consists of attaching three pecksensing switches to the paddle of a conventional pecking key. The force requirements for the three switches are lower, equal to, and higher than the force requirement of a conventional key. Common (C), normally open (NO), and normally closed (NC) contacts on the switches provide input to the computer for counting and timing and to voltage divider and attenuator circuits. The latter are connected to a storage oscilloscope and a polygraph, used for visual monitoring of keypecking.

\section{METHOD}

The test chamber is a ventilated picnic cooler containing a shielded lamp that provides general illumination, a BRS/LVE Model 141-10 grain feeder, a BRS/LVE Model 114-06 water dispenser, a BRS/LVE Model 121-16 pecking key, and a BRS/ LVE Model 111-05 tricolor stimulus projector. The shielded lamp is mounted in the upper left-hand corner of one wall. The grain feeder is in the center of this wall, near the floor. The water dispenser is mounted to the right of the grain feeder. The key is mounted behind a $25-\mathrm{mm}$ circular opening above the grain feeder; the projector is mounted behind the key. 
The standard peck-sensing microswitch was replaced with three switches. Figure 1 is a schematic of the arrangement of switches on the key. One switch was constructed by drilling a hole in the transparent plastic paddle of the key; a stainless steel jeweler's screw is extended through the paddle and makes contact with the galvanized tin plate on which the key is mounted. This screw (to which a length of light, coiled wire is attached) and plate serve as C and NC contacts. A "soft" force of only $.10 \mathrm{~N}$ is required to move the screw away from the plate. The other two switches are C-NO leaf-type switches (removed from a small double-pole single-throw relay) mounted in an offset manner so as to be approximately $1 \mathrm{~mm}$ and $3 \mathrm{~mm}$ away from the paddle. These switches require forces of about $.22 \mathrm{~N}$ and $.61 \mathrm{~N}$, designated as "medium" and "hard."

These switches detect topographical differences in keypecks. Opening of the soft (jeweler's screw) switch defines the onset of all pecks, and closure defines the end. The time between opening and closing defines peck duration. Within each peck, the peak "force" determines the peck's designation. If the soft switch opens and closes without the other switch(es) operating, the peck is designated "soft." If the medium switch closes after the soft opens, the peck is designated "medium." If the hard switch closes after the medium switch, the peck is designated "hard."

Operation of these switches is detected electrically for input to the computer, oscilloscope, and polygraph, as shown in Figure 2. The single-pole double-throw reed relay (EACMIC24AH) provides a NO and NC contact for the jeweler's screw switch. A debounce capacitor is attached to this relay. The NO and NC contacts of the relay, as well as the NO contacts of the other two switches, are connected to the response inputs of BRS/LVE InterACT interface to the NOVA computer. Operation of the switches on the key sets flip-flops in the interface. The computer examines the flip-flops 100 times/sec.

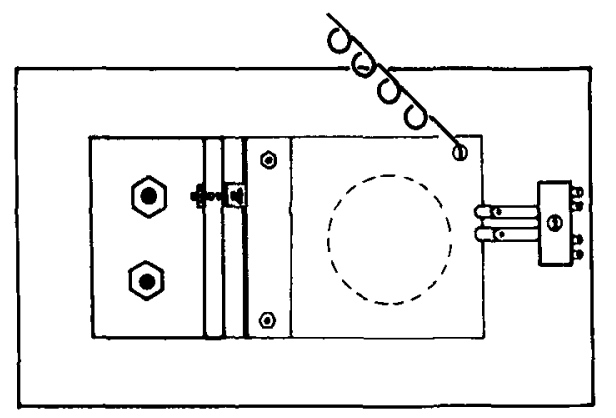

TOP

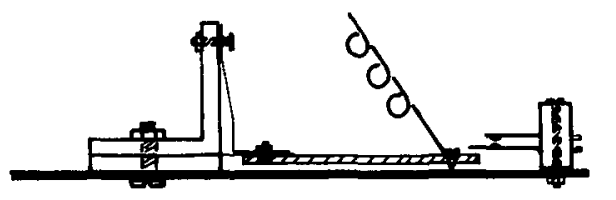

SIDE

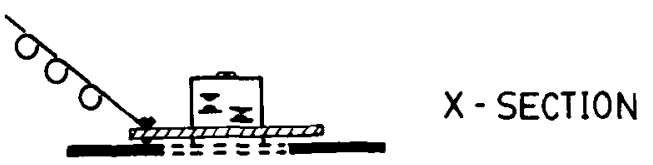

Figure 1. Top, side, and cross-section schematics of the modified pecking key. The standard microswitch was removed from a BRS/LVE Model 121-16 pecking key and replaced by three other switches. One was a jeweler's screw, normally in contact with the galvanized tin plate on which the key was mounted. The other two were leaf-type switches at two distances from the paddle of the key. In the side view, one set of C-NO contacts was omitted for the sake of clarity.

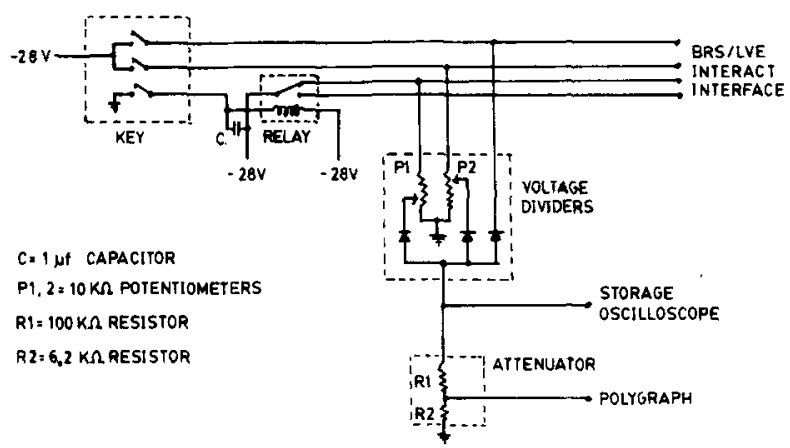

Figure 2. Schematic of electronic circuit used to detect operation of the three switches mounted on the pecking key. See text for details.

The NO contacts of the medium and hard switches and NC contact of the reed relay are "OR gated" through diodes to the storage oscilloscope and through an attenuator to a polygraph. The voltage at the oscilloscope input depends upon the key switch in operation: Approximately $28 \mathrm{~V}$ appears when the top (hard) switch is closed; less voltage appears when the middle (medium) switch is closed, because of the dropping resistor P2; a lower voltage results when the soft switch opens, because the dropping resistor $\mathrm{P} 1$ is greater than $\mathrm{P} 2$. The difference in voltage drops between $R 1$ and $R 2$ produces the input voltage (about $2.5 \mathrm{~V}$ maximuni) to the $\mathrm{J} 5$ input of a Model 7 P5 11 Grass EEG amplifier.

Figure 3 shows a soft, a medium, and a hard peck as seen on a storage oscilloscope. These examples were chosen for their simplicity; other pecks showed considerably more withinpeck force variation.

\section{RESULTS AND DISCUSSION}

Five naive, food and water deprived pigeons were autoshaped to peck a green (red) key that signaled food (water) reinforcement and then were given 25 to 30 daily sessions of 28 trials. On one half of the trials, the key was green and 5 -sec access to mixed grain served as the reinforcer; on the other half, the key was red and $1 \mathrm{ml}$ of water served as the reinforcer. A $5-\mathrm{sec}$ time-out (key light off) separated trials. On each trial, reinforcement was available for the second peck that occurred $25 \mathrm{sec}$ after the start of the trial (i.e., a FI 25-sec schedule with a two-rather than a one-peck requirement).

Because only two pecks were required for reinforcement and because the last peck may have been influenced by the occurrence of the reinforcer, the penultimate peck was chosen for detailed study. Twenty-eight of these pecks were recorded each day, 14 from food reinforcement trials and 14 from water reinforcement trials. The mean durations of the penultimate pecks on food and water reinforcement trials are shown in Figure 4. Two subjects (Birds 1 and 4) showed a duration difference: Pecks on water reinforcement trials (open circles) were longer than pecks on food reinforcement trials (closed circles). Bird 3 was less clear; Birds 2 and 5 showed no consistent differences.

Because pecks (the events between opening and closure of the soft-key switch) rarely consisted of the 

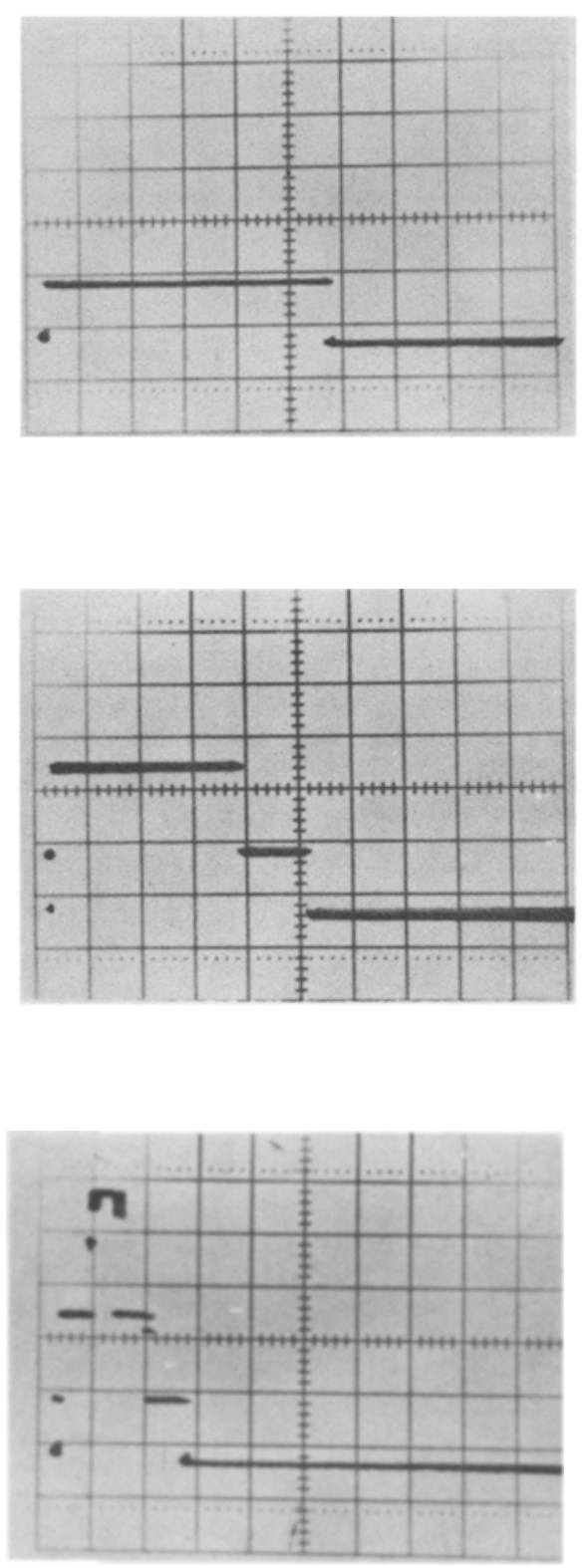

Figure 3. Sample photographs of storage oscilloscope records of keypeck topographies. Each horizontal sweep was initiated by the onset of a peck (i.e., by the opening of the soft switch). Sweep speed was $10 \mathrm{msec} /$ division. Operation of the sof $t$, medium, and hard switches caused the trace to be deflected progressively higher from baseline. The three examples shown would be classified as having soft, medium, and hard peak forces (top to bottom) and durations of 60,50 , and $30 \mathrm{msec}$, respectively.

operation of only one peck-sensing switch, the switch closure data were analyzed in terms of peak "force," and peak force ratios were calculated. The number of soft pecks was tallied for both food and water reinforcement trials. Then the proportion of the total of these pecks that occurred on the food reinforcement trials was calculated. The number of medium pecks was tallied, and the proportion of the total of these medium pecks that occurred on the food trial was calculated. Similarly, the number of hard pecks was counted, and the proportion of such hard pecks that occurred on food trials was calculated. For example, if all of a pigeon's hard pecks occurred during food trials and all of its soft pecks occurred during water trials, the peak force ratio would be 1.0 for hard pecks and .0 for soft pecks.

These three ratios, shown in Figure 5, clearly detected topographical differences in pecking for food and water
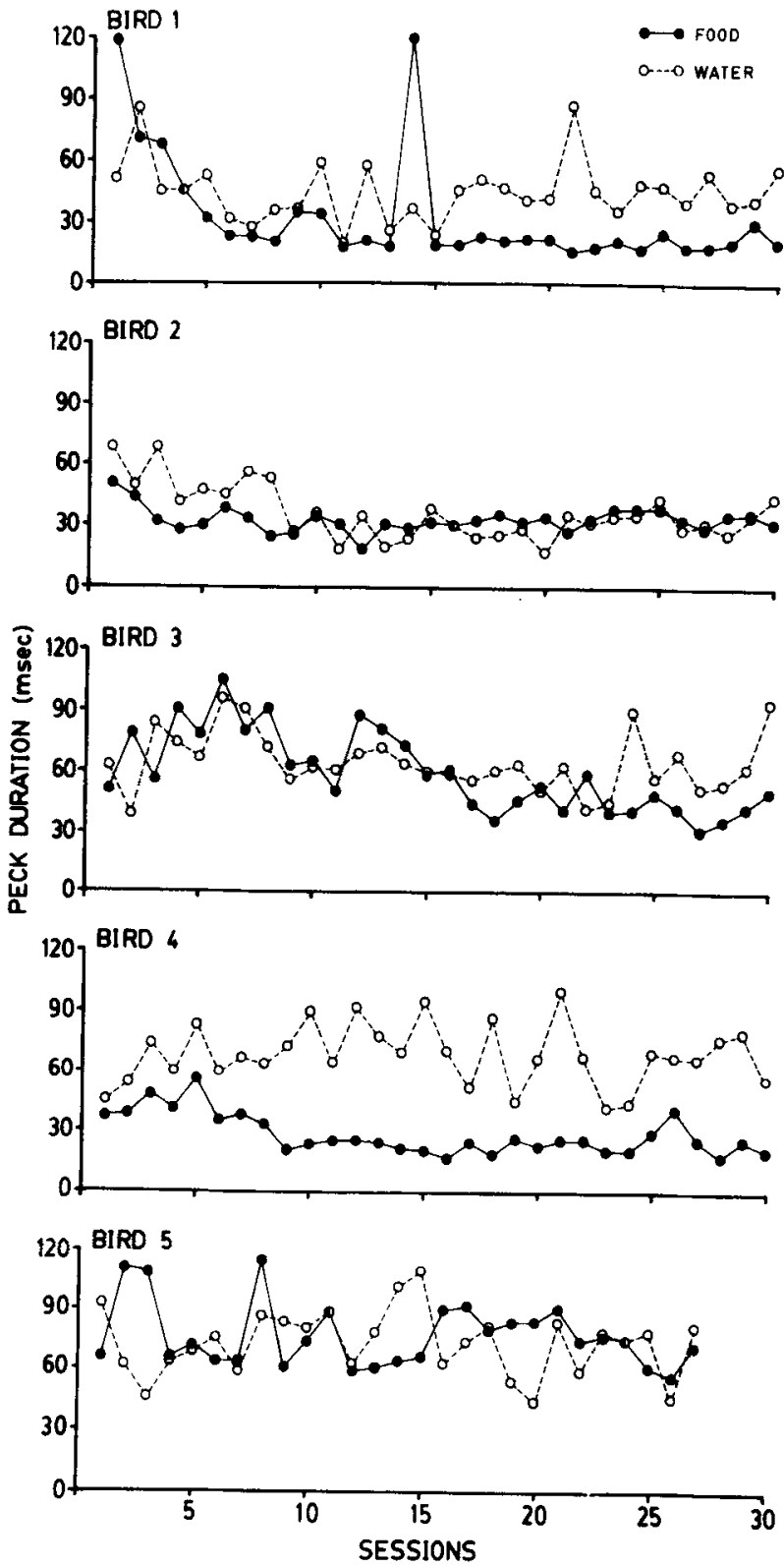

Figure 4. Duration in milliseconds of pecks on food (closed circles) and water (open circles) trials. Duration was defined as the time from the opening of the soft switch until its subsequent closure. This was measured for the penultimate peck on each of the 14 food reinforcement trials and 14 water reinforcement trials of each session; these data were summed for the 14 trials and then averaged and plotted for each session. 

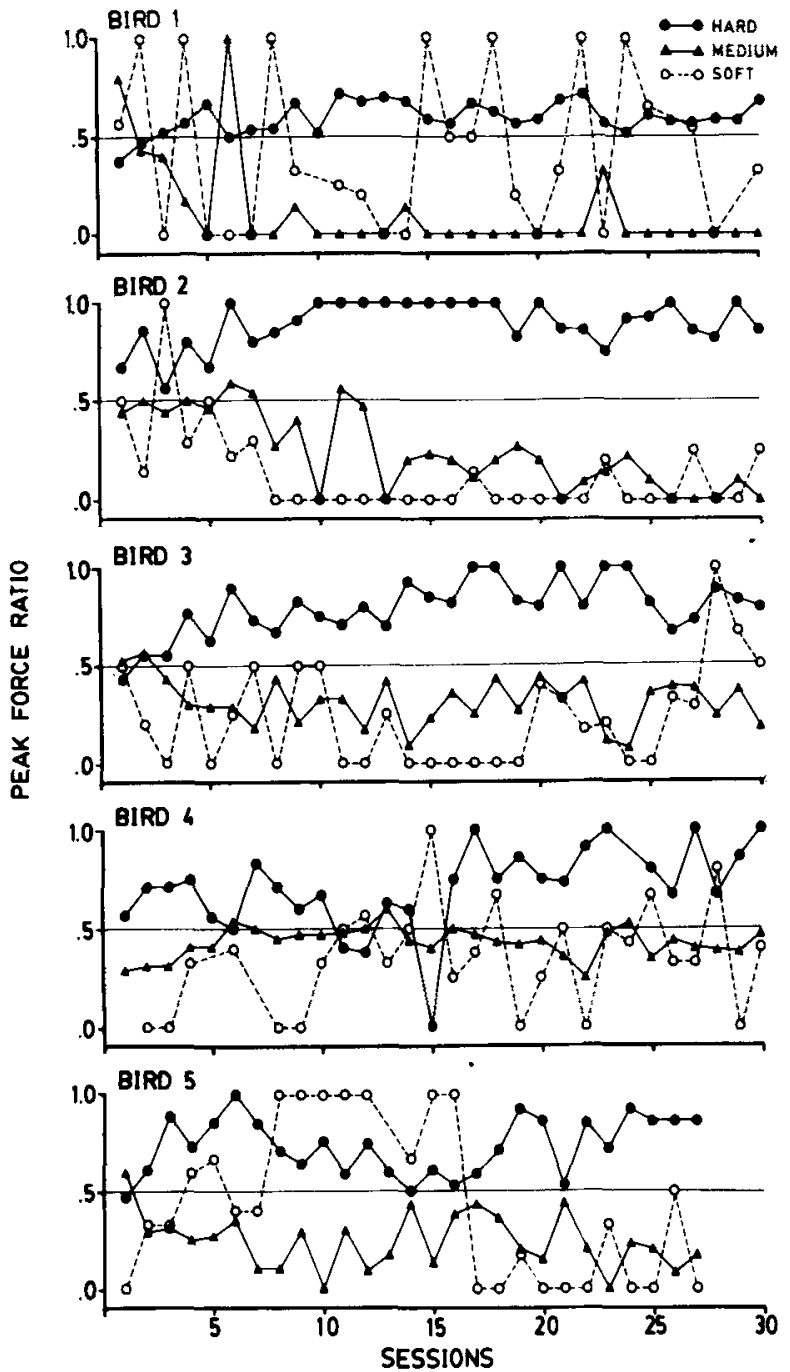

Figure 5. Peak force data for food reinforcement and water reinforcement trials. For each session, the peak force (hard, medium, or soft) of the penultimate peck of each of 14 food reinforcement trials and 14 water reinforcement trials was determined, and the total number of these hard, medium, and soft penultimate pecks was tallied. Then the proportion of eacn of these classes of pecks that occurred on food trials was calculated. The resulting ratios for hard (closed circles), medium (triangles), and soft (open circles) pecks were plotted for each session.

reinforcers: In all subjects, most of the hard pecks (closed circles) occurred on food trials, producing high ratios. Generally, most of medium (triangle) and soft (open circles) peak force pecks occurred on water trials, producing low ratios. Table 1 shows for each bird the percentage of recorded pecks on food and water trials that had a soft, medium, or hard peak force, summed over all sessions of the experiment. Clearly, more pecks fell into the hard category on food trials than on water trials. Thus, the topographical differences between pecks for food and water are revealed both as differences in peak force and as differences in peck duration.
Table 1

Percentage of Recorded Pecks in Each Force Category, Summed Over All Sessions of the Experiment

\begin{tabular}{|c|c|c|c|c|c|c|}
\hline \multirow[b]{2}{*}{ Bird } & \multicolumn{2}{|c|}{ Soft } & \multicolumn{2}{|c|}{ Medium } & \multicolumn{2}{|c|}{ Hard } \\
\hline & Food & Water & Food & Water & Food & Water \\
\hline 1 & 3.0 & 3.7 & 1.8 & 14.5 & 45.2 & 31.8 \\
\hline 2 & 2.6 & 20.3 & 11.1 & 25.8 & 36.3 & 3.9 \\
\hline 3 & 2.7 & 8.7 & 15.1 & 32.3 & 32.2 & 9.0 \\
\hline 4 & 5.1 & 6.9 & 25.9 & 33.9 & 19.0 & 9.2 \\
\hline 5 & 3.9 & 5.9 & 9.1 & 28.6 & 37.0 & 15.5 \\
\hline
\end{tabular}

The measurement of peck force provided by this key, like the measurements of Jenkins and Moore (1973), confounds the effects of force and displacement. As they point out, however, this is preferable to the use of a rigid (isometric) force transducer whose surface may discourage responding or damage a beak. While this "three-force" key may not provide adequate resolution for the analysis of keypeck topographies per se, the data presented here clearly show that it can objectively reveal differences in keypecking for food and water.

\section{REFERENCES}

Boakes, R. A., Poli, M., Lockwood, M. J., \& Goodall, G. A study of misbehavior: Token reinforcement in the rat. Journal of the Experimental Analysis of Behavior, 1978, 29, 115-134.

Hearst, E. Pavlovian conditioning and directed movements. In G. H. Bower (Ed.), The psychology of learning and motivation (Vol. 9). New York: Academic Press, 1975.

Hearst, E., \& Jenkins, H. M. Sign-tracking: The stimulusreinforcer relation and directed action. Austin, Tex: Psychonomic Society, 1974.

Huls, J. H. Instrumental response topographies of rats. Animal Learning \& Behavior, 1977, 5, 207-212.

Jenkins, H. M., Barrera, F. J., Ireland, C., \& Woodside, B. Signal-centered action patterns of dogs in appetitive classical conditioning. Learning and Motivation, 1978, 9, 272-296.

Jenkins, H. M., \& Moore, B. R. The form of the autoshaped response with food and water reinforcers. Journal of the Experimental A nalysis of Behavior, 1973, 20, 163-181.

Schwartz, B., \& Gamzu, E. Pavlovian control of operant behavior: An analysis of autoshaping and its implications for operant conditioning. In W. K. Honig \& J. E. R. Staddon (Eds.), Handbook of operant behavior. Englewood Cliffs, N.J: Prentice-Hall, 1977.

Wolin, B. R. Differences in the manner of pecking a key between pigeons reinforced with food and water. In A. C. Catania (Ed.), Contemporary research in operant behavior. Glenview, Ill: Scott, Foresman, 1968.

Woodruff, G. Behavioral contrast and type of reward: Role of elicited response topography. Animal Learning \& Behavior, 1979, 7, 339-346.

WoodrufF, G., STARR, D. M. Autoshaping of initial feeding and drinking reactions in newly hatched chicks. Animal Learning \& Behavior, 1978, 6, 265-272.

Woodruff, G., \& Williams, D. R. The associative relation underlying autoshaping in the pigeon. Journal of the Experimental Analysis of Behavior, 1976, 26, 1-13.

(Received for publication December 11, 1979; revision accepted March 17, 1980.) 